\title{
NUTRITIONAL EPIDEMIOLOGY
}

\section{Development of a Food Frequency Questionnaire in Japan}

\author{
Chigusa Date', Momoko Yamaguchi ${ }^{2}$, and Heizo Tanaka ${ }^{3}$
}

The three-consecutive-day weighing method, in which foods as raw materials are weighed separately before they are cooked, is the most popular dietary assessment method among Japanese dietitians, because this dietary survey method has been adopted in the national nutrition survey for half a century. Under such circumstances, there have been only a few studies aiming to develop and validate a food frequency questionnaire (FFQ) method. The food list of a few FFQs ever used dealt with individual food items alone, but not mixed dishes. Therefore, a frequency questionnaire was very difficult for people not involved in cooking daily to answer. In order to enable subjects to answer a questionnaire more accurately, a new FFQ which has a food list with 122 single foods and recipes was developed. These foods and recipes were identified from $80524 \mathrm{hr}$-recalls of males and females aged 40-69 years old in Shiso County, Hyogo Prefecture, Japan.

During consecutive 56 or 63 days, 67 junior college students in a dietitian course recorded their diet intake. Within a week after the diet record, they answered the newly developed FFQ. Pearson correlation coefficients between energy adjusted nutrient intakes assessed from the FFQ and those from dietary records were calculated. These correlation coefficients ranged from 0.21 for retinol potency to $\mathbf{0 . 7 4}$ for calcium. These data indicate that the newly developed FFQ provides a useful measurement of many nutrient intakes over a two-month period.

J Epidemiol, 1996 ; 6 : S131-S136.

diet, food, nutrition, dietary questionnaire, dietary assessment, validity

\section{PROBLEMS WITH DIETARY ASSESSMENT IN JAPAN}

In the recent decade it has been increasingly common for epidemiologic studies of nutrition in many countries to use the semi-quantitative food frequency questionnaire (FFQ) for dietary assessment ${ }^{1,4}$. The reasons why the FFQ has become the method most often used by investigators are : firstly it is a quick and relatively inexpensive method compared with several other dietary survey methods, and secondly it is able to measure individuals' or groups' current and past intake. The basic food frequency questionnaire consists of two components : a food list and a frequency response section in which subjects report how often they ate each food item. Questions related to further details of quantity may be appended.
In Japan, however, this method has not been very popular. The most popular method for dietary assessment is a threeconsecutive-day diet record, in which subjects weigh all food items before cooking them. This dietary survey method has been adopted in the national nutrition survey for a long time.

The national nutrition survey held in Japan today originates from the survey conducted in Tokyo by the nutrition department in the Welfare Ministry under the direction of the GHQ in December, 1945. In those days Japanese people were suffering from extreme food shortages after the defeat in World War II in August, 1945. The production of rice, their staple food, had been reduced as low as the level in the early 20th century. Under these deprived circumstances, the primary objective of the first nationwide nutrition survey was to obtain basic data needed to procure food for people in 1946. Thanks

Received and accepted April 18, 1996.

'Department of Public Health, Osaka City University Medical School, Osaka, Japan.

${ }^{2}$ Division of Adult Health Science, National Institute of Health and Nutrition, Tokyo, Japan.

${ }^{3}$ Department of Epidemiology, Medical Research Institute, Tokyo Medical and Dental University, Tokyo, Japan.

Address for correspondence : Chigusa Date, Department of Public Health, Osaka City University Medical School, 1-4-54 Asahimachi Abeno-ku Osaka, 545 Japan. 
to a series of food procurement measures, Japan managed to overcome the deprived conditions and in 1957 the nutritional improvement (eiyou-kaizen) law was established. In accordance with that law, the national nutrition survey has been conducted ever since for the dual purpose of obtaining data on citizens' health conditions, food and nutrient intake, and clarifying relations between nutrition and health.

In the survey the household consumption method has been consistently in use from the very beginning. The national survey had its start in the food-deprived times when meals were simple and mainly dependant on raw materials : there were few processed food items nor opportunities to dine out. This condition made it fairly easy not only to measure raw food prior to its cooking, but also to estimate a particular family's overall intake situation from family-based measurement. However, during high economic growth periods from 1960 to 1974, Japanese people's life styles underwent great changes and became modernized. With the spreading of processed food, there was an increasing tendency to depend upon it for their daily basic food and to dine out. Instead of families eating the same meal together as they used to, now they could afford to eat different dishes according to their individual tastes. This new dietary habit has come to complicate the nutrition survey, making it difficult to estimate individual persons' intake from household consumption data. Therefore, in order to further look into relations between health and food intake, it is imperative to obtain data on individual persons' dietary habits. This is where the FFQ comes in, because it can measure individuals' habitual intake. In the near future, the FFQ will become a more popular dietary assessment method in Japan.

What should be noted about the national nutrition survey is that it has contributed a great deal to the development and dissemination of the FFQ in our country. The survey has been done with randomly selected 6,000 to 7,000 families for as long as half a century with a considerable number of dietitians involved in it. The three-consecutive-day weighing method, in which foods as raw materials are weighed separately before they are cooked, is well known among dietitians.

The FFQ, when it is used in Japan, adopts individual food items or food group, such as beef, pork, eggs, fish, vegetables etc., as its food list. Though we eat single food items in our daily life (eg. "drink milk" and "eat an apple"), we more often eat various food items as mixed dishes. This dietary reality makes it very difficult for subjects not involved in cooking daily to answer a questionnaire regarding their daily food frequency and intake weight of each of such single food items as mentioned above. Besides, since the standard tables of food composition in Japan show the nutrient values of edible raw portions of food per $100 \mathrm{~g}$, the subjects are asked in the FFQ about their usual intake of raw food. And as a means of estimating their intake, they can consult food models and photo books of food items in their raw and uncooked condition. But it is even more difficult for them to estimate the possible intake of single ingredients in the meals before they were cooked, because they did not prepare nor cook their own meals themselves. In order to enable the subjects to answer a questionnaire more accurately, a new FFQ was developed. The new method includes, among questions, both individual food items and mixed dishes. Another feature of the new FFQ is that the subjects are allowed to estimate the intake quantity, not by the weight but by the portion size (volume).

\section{DEVELOPMENT OF A NEW FFQ}

In order to develop a food list, multiple 24 -hr recalls were collected in Shiso County, Hyogo Prefecture in 1991 and 1992. Eight hundred and five residents, aged 40-69 years, were selected randomly from the census table. All reported food items were first ranked according to Block's method ${ }^{3)}$, that is, on the basis of the percentages of nutrients that each food item contributed to the total nutrient intake. The nutrients we were concerned with were total energy, total protein, total fat, vita$\min \mathrm{A}$, and sodium. The percentages were calculated by dividing the nutrients of each food item by the total nutrient amount.

Individual food items were then consolidated into mutuallyexclusive food types, according to their form and type of preparation, nutrient density, and logical association. In constructing the composite food groupings, the first food placed on each rank-order list was designated as food prototype $I$. All the foods contributing at least $0.1 \%$ to the total nutrient intakes were combined to form mutually-exclusive food types.

At first, there were 977 foods and recipes in the 805 recalls. After the grouping of foods and recipes which had different names but similar contents, 444 foods and recipes remained. All the food items contributing at least $0.1 \%$ to the total energy, total protein, total fat or sodium, and $0.2 \%$ to vitamin A were combined into 216 foods and recipes. Then the foods and recipes were consolidated into food types, according to their form and type of preparation, nutrient density, and logical association. Through this procedure, 133 food types were obtained. After the food types which fewer than 10 subjects had eaten were eliminated, 118 food types remained. Furthermore, 4 extra fruit items were added, because the recalls were not collected in their harvest season. As a result, 122 food types were adopted as a food list shown in Table 1 . The final 122 foods and recipes in the questionnaire provided over $95 \%$ of all nutrient supply.

As to the frequency of each food consumption, the response format was not multiple-choice but open-ended. For example, when a subject answered "three times a week" as to a particular food item, its weekly frequency was converted into a daily one by multiplying it by $3 / 7$.

To estimate the individual's usual portion size of each food, two dimensional food model pictures developed by the University of Texas-Houston School of Public Health ${ }^{4}$ were used. Also, there were added to the food model pictures those of regular rice bowls, soup bowls and green tea cups used in Japan. 
Table1. Food list of the Food Frequency Questionnaires(Complete)

\begin{tabular}{|c|c|}
\hline STAPLE FOODS, SNACKS & 62 Stewed deep-fried tofu \\
\hline 1 Curried rice & 63 Stewed soy beans \\
\hline 2 Fried rice or fried rice wrapped with egg & 64 Tempura (deep-fried vegetables) \\
\hline 3 Sushi rice mixed with minced vegetables & 65 Croquette \\
\hline 4 Other sushi,e.g.sushi rice rolled with sea weed, sushi rice & 66 Sauteed thin sliced budock root \\
\hline wrapped with deep fried tofu, etc. & 67 Sauteed vegetables \\
\hline 5 Rice topped with chicken and egg, or rice topped with & 68 Boiled vegetables \\
\hline beef and egg, etc. & 69 Vegetable and potato stew \\
\hline 6 Rice with mixed ingredients & 70 Grated radish \\
\hline 7 Rice broth or, rice with green tea & 71 Baked eggplant \\
\hline 8 Rice ball & 72 Vegetable salad with egg \\
\hline 9 Rice cake & 73 Vegetable salad \\
\hline 10 Steamed rice & 74 Potato salad \\
\hline 11 Noodle soup & 75 Macaroni salad or spaghetti salad \\
\hline 12 Chilled noodles & 76 Salt-flavored pickled vegetables \\
\hline 13 Fried noodles & 77 Dried and salted plums \\
\hline 14 Instant noodle soup & 78 Soy-sauce flavored vegetable products \\
\hline 15 White bread & 79 Soy-sauce seasoned seaweed pruducts. or dried and salted kelp \\
\hline 16 Butter roll & 80 Stewed seafood \\
\hline 17 Margarine, added to food or bread & 81 Toasted purple laver \\
\hline 18 Butter, added to food or bread & 82 Condiment sprinkled on cooked rice \\
\hline 19 Cheese & 83 Miso soup \\
\hline 20 Confectionary bun & 84 Other soup \\
\hline 21 Sandwich & 85 Beef stew, chowder or potage \\
\hline 22 Hamburger sandwich or bun with non-confectionary fillings & 86 Sukiyaki or hodgepodge dish (fish, meat, vegetables, etc.) \\
\hline 23 Japanese pizza with vegetables & 87 Hodgepodge dish (fish paste, egg, tofu.etc) \\
\hline DISHES & 88 Venegar-flavored seafood and vegetables \\
\hline 24 Fried chicken & DAIRY FOODS \\
\hline 25 Pork cutlet & 89 Whole milk or coffee flavored milk \\
\hline 26 Hamburger & 90 Low fat milk or Skim milk \\
\hline 27 Beef steak or teriyaki chicken & 91 Yogurt \\
\hline 28 Fried meat & 92 Lactic acid bacteria beverages \\
\hline 29 Broiled beef & 93 Ice cream or ice milk \\
\hline 30 Broiled chicken (Yaki-tori) & BEVERAGES \\
\hline 31 Liver-based dishes & 94 Jananese green tea \\
\hline 32 Fried sausage & 95 Fruits juice or vegetable juice (fresh, frozen, or canned) \\
\hline 33 Ham or roasted pork & 96 Carbonated beverage (with sugar) \\
\hline 34 Meat-and-vegetable stew & 97 Coffee or canned coffee \\
\hline 35 Sweet and sour pork or fried vegetables mixed with pork, seafood, etc. & 98 Sake (fermented alcoholic beverage) \\
\hline 36 Gyoza (Chinese dishes) & 99 Beer \\
\hline 37 Fried fish or deep fried fish & 100 Shochu (distilled alcoholic beverage) \\
\hline 38 Stewed cuttle fish, prawns, or octopus & 101 Chu-hai (shochu diluted with carbonated beverage) \\
\hline 39 Stewed white meat fish & 102 Whiskey \\
\hline 40 Stewed dark meat fish & 103 Wine (red wine or white wine) \\
\hline 41 Other stewed fish & FRUITS \\
\hline 42 Broiled white meat fish & 104 Mandarins, Oranges, or Grapefruit \\
\hline 43 Broiled dark meat fish & 105 Watermelon \\
\hline 44 Other broiled fish & 106 Japanese pears \\
\hline 45 Broiled salted and semi-dried sardines & 107 Bananas \\
\hline 46 Raw fish or raw shellfish & 108 Grapes \\
\hline 47 Salted cod roe & 109 Apples \\
\hline 48 Semi-dried sardine fries & 110 Japanese persimmons \\
\hline 49 Fish paste & 111 Chestnuts \\
\hline 50 Soy-sauce seasoned fish products & 112 Muskmelons \\
\hline 51 Dried cuttle fish & 113 Strawberries \\
\hline 52 Salted and semi-dried seafood & SWEETS, BAKED GOODS, NUTS \\
\hline 53 Fried egg roll & 114 Sweetend bean paste \\
\hline 54 Fried egg sunny-side up & 115 Rice craker \\
\hline 55 Vegetable omelet & 116 Deep-fried wheat flour confectionery \\
\hline $56 \mathrm{Egg}$ pudding & 117 Chocolates \\
\hline 57 Raw egg & 118 Sponge cake \\
\hline 58 Steamed egg & 119 Cake (home baked or ready made) \\
\hline 59 Fermented soy beans & 120 Cookies (home baked or ready made) \\
\hline 60 Tofu (chilled or boiled) & 121 Beans (parched and salted peas. or fried broad beans) \\
\hline 61 Dried tofu-dish & 122 Nuts \\
\hline
\end{tabular}


Table 2. Comparison of mean daily nutrient intake using diet records and food frequency questionnaire

\begin{tabular}{|c|c|c|c|c|c|c|}
\hline & \multicolumn{2}{|c|}{ Diet records } & \multicolumn{2}{|c|}{ The first FFQ } & \multicolumn{2}{|c|}{ The second FFQ } \\
\hline & Mean & SD* & Mean & SD & Mean & SD \\
\hline Energy (kcal) & 1415 & 296 & 1450 & 328 & 1299 & 348 \\
\hline Protein $(\mathrm{g})$ animal & 29.3 & 7.5 & 29.1 & 9.9 & 25.2 & 9.9 \\
\hline Protein $(\mathrm{g})$ vegetable & 22.1 & 5.0 & 23.8 & 5.9 & 21.6 & 6.8 \\
\hline Fat $(\mathrm{g})$ animal & 20.3 & 6.0 & 19.5 & 7.8 & 17.3 & 6.8 \\
\hline Fat $(\mathrm{g})$ fish & 2.5 & 1.1 & 2.9 & 1.6 & 2.3 & 1.4 \\
\hline Fat $(g)$ vegetable & 24.9 & 7.3 & 22.8 & 6.7 & 19.6 & 7.4 \\
\hline Carbohydrate (g) & 188 & 44 & 200 & 45 & 183 & 49 \\
\hline Calcium (mg) & 353 & 125 & 438 & 163 & 388 & 159 \\
\hline Sodium (mg) & 3042 & 708 & 3510 & 1236 & 2975 & 1236 \\
\hline Potassium (mg) & 1589 & 481 & 1767 & 556 & 1524 & 553 \\
\hline Retinol potency (IU) & 1708 & 598 & 1704 & 778 & 1456 & 845 \\
\hline Retinol $(\mu \mathrm{g})$ & 242 & 130 & 257 & 183 & 214 & 165 \\
\hline Carotene $(\mu \mathrm{g})$ & 1587 & 663 & 1489 & 743 & 1302 & 942 \\
\hline Vitamin C (mg) & 59 & 34 & 77 & 38 & 63 & 36 \\
\hline Vitamin E potency (mg) & 3.8 & 1.2 & 3.8 & 1.2 & 3.2 & 1.2 \\
\hline
\end{tabular}

* standard deviation

\section{VALIDATION OF THE FFQ}

The FFQ mentioned above was validated against consecutive 56 or 63 days' diet records. The subjects were 67 junior college students ( 3 males and 64 females, aged 19-26 years) taking a dietitian course.

Food consumption was recorded from April through June for 56 days by 32 students in 1993, and for 63 days by 35 students in 1994. Within 1 week after the dietary record period was finished, the first FFQ was conducted; with respect to each of the
122 food items, the subjects were asked by a trained interviewer to indicate the frequency of consumption and the average amount during the above-mentioned dietary record periods in both years. A week after the first FFQ, the second one was conducted with the use of the same method. The average nutrient intake was calculated from each individual dietary record and designated as the gold standard. The validation of the FFQ was checked against correlation coefficients between the gold standard and the first FFQ. Furthermore, the reproducibility of the FFQ was examined against correlation coeffi-

Table 3. Pearson correlation coefficients between nutrients estimated by the first food frequency questionnaire and the average of consective 56 or 63 diet records

\begin{tabular}{lcc}
\hline & $\begin{array}{c}\text { The first food frequency questionnaire vs. } 56 \text { or } 63 \text { diet records } \\
\text { Anadjusted }\end{array}$ & $\begin{array}{c}\text { Adjusted** } \\
\text { Energy }\end{array}$ \\
Protein (animal) & 0.65 & - \\
Protein (vegetable) & 0.70 & 0.60 \\
Fat (animal) & 0.62 & 0.44 \\
Fat (vegetable) & 0.66 & 0.46 \\
Carbohydrate & 0.47 & 0.54 \\
Calcium & 0.65 & 0.58 \\
Sodium & 0.70 & 0.74 \\
Potassium & 0.46 & 0.26 \\
Retinol potency* & 0.52 & 0.50 \\
Retinol* & 0.40 & 0.21 \\
Carotene* & 0.54 & 0.53 \\
Vitamin C* & 0.42 & 0.25 \\
Vitamin E potency* & 0.35 & 0.38 \\
\hline
\end{tabular}

Data are besed on responsed of 67 students

* Correlation coefficient is shown as Spearman correlation coefficient

** Intakes adjusted using Willett's method 
Table 4. Pearson correlation coefficients between nutrients estimated by the first and those by the second food frequency questionnaire conducted one week apart

\begin{tabular}{lc}
\hline & $\begin{array}{c}\text { The first food frequency questionnaire vs. the second food frequency questionnaire } \\
\text { Unadjusted }\end{array}$ \\
\hline Energy & 0.69 \\
Protein (animal) & 0.78 \\
Protein (vegetable) & 0.64 \\
Fat (animal) & 0.72 \\
Fat (vegetable) & 0.70 \\
Carbohydrate & 0.67 \\
Calcium & 0.78 \\
Sodium & 0.75 \\
Potassium & 0.77 \\
Retinol potency & 0.53 \\
Retinol & 0.28 \\
Carotene & 0.39 \\
Vitamin C & 0.73 \\
Vitamin E potency & 0.74 \\
\hline
\end{tabular}

Data are besed on responses of 67 students

cients between the first FFQ and the second one.

Mean nutrient intake values estimated from the first and second FFQs and the diet records are shown in Table 2. Both methods yielded almost the same intake of all the nutrients.

Pearson correlation coefficients between the nutrient intake estimated from the FFQ and the one from the diet records are shown in Table 3. Correlation coefficients are shown in two types : adjusted one for total energy intake by Willett's method $^{5}$ and unadjusted one. Unadjusted correlation coefficients varied from 0.35 for vitamin $\mathrm{C}$ to 0.70 for animal protein, with most values between 0.5 and 0.7 . After adjustment for total energy, most of the adjusted values were between 0.4 and 0.6. Adjustment for total energy decreased correlation coefficients for most nutrients except vegetable fat, calcium, sodium, and vitamin $\mathrm{C}$.

The correlation coefficents between nutrient intake estimated from the first and the one from the second FFQ are presented in Table 4 to show the reproducibility of the FFQ. The correlation coefficents varied from 0.64 for vegetable protein to 0.78 for calcium, with most values above 0.7 except vitamin A.

These data indicate that the FFQ provides a useful estimation of intake for many nutrients over a two-month period.

\section{REFLECTION ON THE DEVELOPED FFQ}

There was, however, a problem in administrating the FFQ : An interview with one subject took as long as 1 hour.

Firstly, the problem stemmed from dealing with too many food items. In this study we used Block's approach ${ }^{33}$ to identify foods that contribute most importantly to the total absolute intake. Consequently, 122 food items were adopted as a food list. Hence the number must be reduced in the future. Since in most epidemiologic applications, ranking individual intake is its primary objective $e^{5)}$, food items to classify individuals by should be selected, because food intake varies from person to person. Willette et al. ${ }^{6}$ and Overvad et al. ${ }^{7)}$ adopted stepwise multiple regression analysis to identify important foods in predicting individual nutrient intake. We will also adopt the same procedure in reducing the number of food items.

Secondly, the long interview time was also due to the estimation of the portion size by open-ended questionnaires. Our FFQ consists of a food list, a frequency response section, and a portion size section which is estimated by using food model pictures. To shorten the interview time, we have devised a picture booklet of 122 food items (foods and mixed dishes) in their actual sizes. The typical portion was made from $24 \mathrm{hr}$ recalls of 805 people which we had used for the development of the food list.

Also, there were two problems with the validation study. The first problem was with the length of the study period. We examined the validity of estimating the past 2-month-nutrient intake against the FFQ, but judging from seasonal variations in dietary intake, this period proved to be too short to examine individual's usual intake over a long period of time. The other problem with this validation study has to do with the subjects : since they were students of the dietitian course, they might have been different from ordinary adults in a community to whom we would like to apply the FFQ in examining relationships between dietary intake and health status.

Therefore we have started a new one-year validation study with adults (aged over 30 , males and females) in two communities in Osaka--spring, summer, autumn and winter with 7 days dietary records per session. 


\section{REFERENCES}

1. Willett W C. Future directions in the development of food-frequency questionnaires, Am J Clin Nutr, 1994 ; 59 (suppl.) : 171S-174S.

2. Kushi L H. Gaps in epidemiologic research methods : design considerations for studies that use food-frequency questionnaires, Am J Clin Nutr, 1994 ; 59 (suppl.) : 180S$184 \mathrm{~S}$.

3. Block G, Dresser C M, Hartman A M, and Carroll M D. Nutrient sources in the American diet : Quantitative data from the NHANES II survey. I. Vitamins and minerals, Am J Epidemiol, 1985 ; 122 : 13-26.

4. Thompson F E, Byers T, and Kohlmeire L. IV Examples of dietary assessment tools. in Dietary Assessment
Resource Manual, J Nutri, 1994 ; 124 (suppl.) : 2269S.

5. Willett W C. Food frequency method. In ; Nutritional Epidemiology. Oxford University Press, New York, Oxford, $1990:$ 69-91.

6. Willett W C, Sampson L, Stampfer M J , Rosner B, Bain C, Witschi J, Hennekens $\mathrm{C} H$, and Speizer F E. Reproducibility and validity of a semiquantitative food frequency questionnaire, Am J Epidemiol, 1985 ; 122 : 51-65.

7. Overvad K, Tjønneland A, Haraldsdottir J, Ewertz M, and Jensen $\mathrm{O} M$. Development of a semiquantitative food frequency questionnaire to assess food, energy and nutrients intake in Denmark, Int J Epidemiol, 1991 ; 20 : 900-905. 